\title{
Günter Frankenberg's Comparative Constitutional Studies: Between Magic and Deceit
}

\author{
Jud Mathews*
}

(Received 1 June 2019; accepted 15 June 2019)

\begin{abstract}
Constitutions traffic in magic and deceit, argues Günter Frankenberg, promising freedom and democracy even as they underwrite the exercise of coercive power on a massive scale. Scholars should approach constitutions with a healthy skepticism, but, Frankenberg contends, most mainstream scholars are too credulous, especially regarding the claims of liberal constitutionalism. Comparative Constitutional Studies serves as his corrective to the perceived blind spots and predilections of mainstream comparative constitutional scholarship, and it gives attention to little-known constitutions, forgotten histories, and alternatives to liberal constitutionalism. It's a rich, challenging, and valuable book, one that takes the reader to some off-the-beaten-track places and offers some new perspectives on well-studied landmarks. It does not, however, represent such a radical break from mainstream scholarship as the author supposes, both because the book's own analysis, in practice, is not deeply unconventional, and because mainstream scholarship is more diverse than Frankenberg gives it credit for.
\end{abstract}

Keywords: Comparative constitutional law; constitutionalism

The subtitle of Günter Frankenberg's recent book Comparative Constitutional Studies ${ }^{1}$ is Between Magic and Deceit - and between its covers, Frankenberg practices a deceit of his own. He identifies the book as a "textbook," but don't believe it: this text is too original, personal, subversive, intellectually demanding, and witty to qualify. Textbooks teach their readers the standard methods and key findings in a field of study. Frankenberg's book, by contrast, undertakes a frontal assault on central aspects of what he regards as "the mainstream" in comparative constitutional law. At every turn, the book challenges those scholars who work in the field to do better: To question our unstated normative assumptions, our selection of cases, and our methods.

The book is animated by a doubled skepticism: Scholars have to be wary of constitutions, and also of the dominant comparative constitutional discourse. In other words, we must always stay awake to the possibility that constitutions may be lying to us - and that scholars may be lying to themselves, without knowing it. Vigilance is required, first of all, because constitutions promise magic - a "more perfect union"; 2 to "Heal the divisions of the past and establish a society based on democratic values, social justice and fundamental human rights"; "to secure to all its citizens JUSTICE ..., LIBERTY . ., EQUALITY ..., [and] FRATERNITY"4_while at the same time

${ }^{\star}$ Jud Mathews is a Professor of Law at Penn State Law and an Affiliate Professor at Penn State's School of International Affairs. https://pennstatelaw.psu.edu/faculty/mathews. Email: jcm41@psu.edu.

${ }^{1}$ Frankenberg et al., Comparative Constitutional Studies: Between Magic and Deceit (Edward Elgar ed., 2018).

${ }^{2}$ U.S. CONST. pmbl.

${ }^{3}$ S. AFr. CONST. pmbl., 1996.

(C) The Author(s) 2020. Published by Cambridge University Press on behalf of the German Law Journal. This is an Open Access article, distributed under the terms of the Creative Commons Attribution licence (http://creativecommons.org/licenses/by/4.0/), which permits unrestricted re-use, distribution, and reproduction in any medium, provided the original work is properly cited. 
licensing, and perhaps disguising, the exercise of coercive power on a massive scale. Frankenberg argues that the dominant discourse in comparative constitutional scholarship is also suspect. The mainstream view, according to Frankenberg, supposes an underlying unity to constitutional enterprises playing out around world:

[C]omparativists downplay differences, proceed with an eye towards convergence or rapproachement, claim that there is a significant degree of congruence between social problems and their constitutional solutions, and argue that the areas of agreement and overlap clearly outweigh significant contextual, structural or functional diversity. This unitary vision is criticized as being intensely Anglo-Eurocentric, thereby sustaining the conceptual dominance and ideological hegemony of Western constitutionalism. ${ }^{5}$

For Frankenberg, this orientation is no accident, but the reflection of methodological, theoretical, and ideological commitments-commitments that are often only implicit, and, in Frankenberg's view, that should be subjected to careful interrogation. Chief among these commitments are an unreflective functionalism - in which constitutions figure as solutions to problems, but problems as conceptualized by the outside analyst rather than participants in the system-and an operating assumption that liberal constitutionalism is "real" constitutionalism, with the result that constitutional analysis becomes measuring degrees of divergence from this ideal.

What, then, is the way forward? Part of Frankenberg's answer is attitude: One defense against deception is cultivating a habit of skepticism, an eternal vigilance against falling into conventional wisdom. More concretely, he aims here "to look at as many constitutions as possible, notably at other-constitutions" - those neglected or treated as marginal by most scholars, such as Haiti's short-lived 1801 and 1805 constitutions. ${ }^{6}$ Also, recognizing that constitutions do-and aremany things at the same time, he prescribes a "layered narrative" that combines different reading strategies. Constitutions need to be read as literary texts and subjected to a penetrating, even deconstructive, reading. At the same time, constitutions should be read as constructive plans: designs for institutions and power structures. What is more, constitutions must be read as products of transfer and bricolage: These are texts that talk to each other.

Besides describing his methods, in Part I Frankenberg also inventories the concepts he uses in comparative constitutional work, and here too, he stresses less familiar approaches and viewpoints. To be sure, the standard-issue contemporary constitution, fixated on the design challenge of building a democratic, law-governed, free, and stable polity - the "codified constitution," in his terms-figures among his constitutional archetypes. But he gives equal airtime to: The "constitution as manifesto," with a distinctive rhetoric and agenda; the "constitution as contract," negotiated among elite interest groups; and the "constitution as programme/plan," pioneered by communist regimes. Even in cataloging the basic building blocks of constitutional architecture, Frankenberg challenges conventional wisdom, downplaying, for instance, the importance of rights. Notwithstanding their centrality to contemporary scholarly discourse, Frankenberg argues, constitutional rights often mean little for the truly vulnerable. Frankenberg focuses attention instead on constitutional values and constitutional duties. Constitutional values, in particular, have legs, in that values talk is a way of spreading responsibility for constitutional culture beyond the state and into society.

Similarly, in enumerating the varieties of constitutionalism, Frankenberg treats liberal constitutionalism less as the apotheosis of the genus, and more as one of many constitutionalisms incapable of fully delivering what it promises. Front and center in Frankenberg's treatment is liberal constitutionalism's particular admixture of magic and deceit. The emphasis in liberal

${ }^{4}$ INDIA CONST. pmbl.

${ }^{5}$ Günter Frankenberg, Comparative Constitutional Studies: Between Magic and Deceit 69 (2018).

${ }^{6} I d$. at 12 . 
constitutional discourse on rights, the separation of powers, and the primacy of "we the people" oversells the constitution's capacity to restrain the state power that it underwrites. In Frankenberg's view, "in critical situations, the Leviathan is back, if dressed in a cashmere overcoat." ${ }^{7}$ Moreover, the unwavering focus on the state serves as a form of misdirection, drawing attention away from the accumulation and exercise of private power.

The most prominent competitor to liberal constitutionalism today is political constitutionalism, which trusts legislatures rather than courts to keep constitutional commitments. But political constitutionalism also promises more than it can deliver, overstating the role of "the people" in parliamentary sovereignty regimes. And alongside these, Frankenberg presents a rich variety of other constitutionalisms: Egalitarian constitutionalism (focused on leveling up along one or more dimensions); conservative constitutionalism (embedding a suspicion of uncabined democracy); social constitutionalism (setting the powers of state to addressing the social question), transformative constitutionalism (aimed at a progressive realization of an emancipatory modernization project), and marxist-leninist constitutionalism (a variant of transformative constitutionalism).

The second part of the book, on constitutional transfer and experimentalism, underscores that constitution-making is, and has always been, a transnational process. Frankenberg cheekily imagines the market for constitutional ideas as an IKEA, where customers can choose among a vast array of existing provisions (some assembly required). At the heart of this part of the book is a case study that traces conceptions of constitutional monarchy as they passed through a succession of nineteenth-century European states, changing with each stop. The account aptly illustrates the twin truths about "the migration of constitutional ideas": 8 That nothing is wholly original, and that everything becomes new in a new setting.

The third and final part of the book addresses the idea of "constitution as order." The focus here is on the work-sometimes dirty work - that constitutions do to keep society together. There are a number of aspects to this: Constitutions promote social integration (to different degrees, depending on the form of constitutionalism at issue); they manage high-stakes political conflict, including through strategies for converting "do-or-die" conflicts into "more-or-less" conflicts; and they define the borders of political community, which necessarily means placing some outside of it. Frankenberg also engages with the challenge of designing constitutions for states facing a risk of partition or fragmentation. Strategies range from the denial or suppression of difference (as in China's 1982 Constitution) to accommodation (as in Bolivia's 2009 Constitution). Frankenberg also canvasses how constitutions seek to cabin, control, and define states of exception. For Frankenberg, the paradigmatic justification for suspending the normal rules is the natural emergency, and governments seek to justify emergency powers by framing man-made crises in similar terms. Frankenberg assimilates the colony, the slave plantation, and the concentration camp to the state of exception: All, he argues, are settings where the exception has become the rule for defined outgroups.

This is a rich, challenging, and valuable book, one that takes the reader to some off-thebeatentrack places and offers some new perspectives on well-studied landmarks. Ironically, one of the reasons the book succeeds is that it does not quite deliver what it promises, namely, a complete rejection of methods and concepts of mainstream comparative constitutional scholarship. For instance: the book shines in its in-depth engagement with constitutional texts. But notwithstanding the head feints in the direction of deconstruction, Frankenberg's handling of the texts is light on feats of Derridean derring-do and heavy on sensible, careful, but fundamentally conventional readings. There's substantial value in this approach, because many of these texts are off the radar, and Frankenberg's work brings them a welcome attention.

Similarly, despite the talk of layered narratives, much of the book is given over to the cuttingedge method pioneered by Carl Linnaeus in the eighteenth century: taxonomy. Frankenberg offers

\footnotetext{
${ }^{7} I d$. at 95 .

${ }^{8}$ The Migration of Constitutional Ideas (Sujit Choudhry ed., 2007).
} 
the reader, among other menus, four constitutional archetypes; four elements of constitutional architecture; six forms of constitutionalism; and three models of constitutional monarchy. This is no complaint, although one might quibble over whether the categories that Frankenberg devises are collectively comprehensive and individually distinct. What gives Frankenberg's taxonomies their value is the hard empirical work he puts into exploring the understudied regimes, including those belonging to the past, and his unwillingness to settle for a set of received categories to slot them into.

Every choice involves trade-offs, including those that Frankenberg makes in his book. Two of Frankenberg's key methodological commitments are to consider a large number of constitutions and to pay close attention to their text. It follows that little attention is left for what is outside the text. The result is an approach that is expansive in one sense, and limited in another. The book's title-Contemporary Constitutional Studies-is apt: The focus here is squarely on the constitutions themselves, or more precisely, on their texts. This approach condemns us to miss much, if what we care about is the real work that constitutions do in society. Frankenberg faults mainstream scholarship for focusing too much on cases. He has a point-it is easy for scholars to fetishize cases - but at the same time, cases are an important channel through which constitutions have an effect on the world around them, and they offer the analyst a way to track how a constitution's meaning on the ground can change over time. More generally, Frankenberg's near-exclusive focus on texts does not allow him much scope to take account of constitutional development, apart from formal amendments. It seems almost as though for Frankenberg, as for American textualists, the constitution is its text.

Frankenberg's critique of mainstream comparative constitutional law scholarship has some bite, but it invites objections of its own. Frankenberg is right, of course, that we should not look (as Ran Hirschl has put it) to "the constitutional experience of half a dozen (on a good day) politically stable, economically prosperous, liberal democracies" and flatter ourselves that we have covered the waterfront. At the same time, our selection of cases should be informed by the questions to which we seek answers. If our question is about the effect of a particular institutional feature, for instance, a strategy of comparing most similar cases-to hold as much else constant as possible - can make sense. More generally, constitutions can lay claim on our attention for different reasons. To the extent we want a comprehensive picture of the world's constitutions, all are equally relevant. But if we are seeking viable models for handling issue $x$, it makes sense to be more selective. To offer an extreme example, Frankenberg opens his book with a discussion of Syria's 2012 constitution, put together by the Assad regime during the civil war. Frankenberg all but calls it a sham constitution. It is worth knowing about the phenomenon of sham constitutions, ${ }^{10}$ but there are also good reasons why scholars have not subjected the provisions of Syria's 2012 constitution to minute analysis.

Frankenberg's critique also has less bite today than it would have had in the past, because the mainstream in comparative constitutional law is not what it once was. A casual stroll through any recent volume of $I \bullet C O N$ will confirm that comparative constitutional law today engages deeply with different kinds of constitutions from different regions. The field itself is also increasingly transnational, with scholars from around the world collaborating and making important contributions. The empirical turn in comparative constitutional law, about which Frankenberg has little to say, has done much to broaden the field's horizons past the small roster of usual suspect countries to which Hirschl refers. Good empirical work is valuable, among other reasons, because data can challenge old assumptions about what the dominant practices are. The empirical work of scholars such as Zachary Elkins, Tom Ginsburg, David Law, and Mila Versteeg has done much to challenge conventional wisdom about what is the norm in constitutions worldwide. Also, to the extent that the scholarly discourse ever presupposed a global convergence towards the liberal

\footnotetext{
${ }^{9}$ Ran Hirschl, Comparative Matters: The Renaissance of Comparative Constitutional Law 205 (2014).

${ }^{10}$ For more on the topic, see David S. Law \& Mila Versteeg, Sham Constitutions, 101 CALIF. L. REV. 863 (2013).
} 
constitutional model, the rise of illiberal regimes around the world in recent years has unsettled that assumption. As Frankenberg reminds us, liberal constitutionalism is one option among many, and those who embrace it as an ideal have to make the case for it.

The distance, then, between Frankenberg and other contemporary scholars of comparative constitutional law may not be so great as he supposes-both because his methods, in practice, turn out not to be especially radical, and because mainstream scholarship has already heeded at least some of the precepts he preaches. None of this diminishes the value of his book, which exposes the reader to understudied regimes, sorts the constitutional world, past and present, into an original conceptual framework, and, perhaps most importantly, admonishes us to be always attentive to constitutions' power to enchant and deceive.

Cite this article: Mathews J (2020). Günter Frankenberg's Comparative Constitutional Studies: Between Magic and Deceit. German Law Journal 21, 299-303. https://doi.org/10.1017/glj.2020.5 